\title{
The Thrombolysis in Myocardial Infarction (TIMI) Study Group experience
}

\author{
Eugene Braunwald, MD, and Marc S. Sabatine, MD, MPH
}

\begin{abstract}
The Thrombolysis in Myocardial Infarction (TIMI) study group, an academic research organization, was formed in 1984 with initial support from the National Heart, Lung, and Blood Institute. Its initial goal was to compare the effects of the then-new thrombolytic agent, recombinant tissue plasminogen activator, with streptokinase. The TIMI study group has remained active since then and has completed 50 multicenter clinical trials. The TIMI network now collaborates with more than 1000 separate sites in 45 countries on 5 continents. In addition to thrombolytic agents, TIMI has studied antithrombotic, antiplatelet, anti-ischemic, lipid lowering, and anti-inflammatory drugs. TIMI has also established robust biomarker and pharmacogenetics programs, and has devised a panel of risk assessment scores that are widely used. TIMI is currently conducting 7 large trials worldwide on novel agents designed to reduce the morbidity and mortality of a variety of cardiovascular disorders. (J Thorac Cardiovasc Surg 2012;144:762-70)
\end{abstract}

\section{THE ORIGINS OF TIMI}

Although the idea of reperfusing infarcting myocardium in the management of patients with acute myocardial infarction (MI) was developed in the early 1970s, it had its roots much earlier. In 1935, Tennant and Wiggers ${ }^{1}$ demonstrated, in open chest anesthetized dogs, that immediately after occlusion of a major coronary artery the contraction of the myocardium perfused by the occluded vessel became severely impaired. Function recovered only if the obstruction was relieved within 23 minutes. In 1941, Blumgart, Gilligan, and Schlesinger ${ }^{2}$ also studied the consequences of coronary artery occlusion and noted by both gross and microscopic examination that no infarction occurred in dogs in which reperfusion was carried out up to 20 minutes after occlusion and that with longer occlusions, the size of the infarct was proportional to the duration of the occlusion. Although these early experiments demonstrated that myocardial necrosis after coronary occlusion could be minimized and even prevented by early reperfusion, neither of these groups suggested that reperfusion was a potential therapeutic intervention in patients with an evolving infarction.

In 1969, one of us (E.B.) ${ }^{3}$ proposed that the development of cardiac pump failure could be reduced and that clinical outcome improved by limiting the quantity of myocardium that becomes necrotic after the onset of acute MI. This

From the TIMI Study Group, Cardiovascular Division, Brigham and Women's Hospital, and the Department of Medicine, Harvard Medical School, Boston, Mass.

The TIMI Study Group has received research grants from Abbott, Astra Zeneca, Amgen, Bayer Healthcare, Bristol Myers Squibb, Daiichi Sanko, Eli Lilly, GlaxoSmithKline, Merck (SPRI), Pfizer, Roche (Diagnostics), Sanofi Aventis, and Johnson \& Johnson.

Disclosures: Dr Sabatine has served on the Scientific Advisory Boards of Amgen, GlaxoSmithKline, Merck, Pfizer, and Sanofi Aventis. Dr Braunwald has served as a consultant for Merck (no compensation), Amorcyte, Daiichi Sankyo, Medicines Co, Ikaria, CardioRentis, Sanofi Aventis, and CVRx (no compensation).

Address for reprints: Eugene Braunwald, MD, TIMI Study Group, 350 Longwood Ave, Boston, MA 02115 (E-mail: ebraunwald@partners.org).

$0022-5223 / \$ 36.00$

Copyright (C) 2012 by The American Association for Thoracic Surgery

http://dx.doi.org/10.1016/j.jtcvs.2012.07.001 hypothesis was tested again in open chest anesthetized dogs, and it was observed that the extent and severity of ischemic damage secondary to coronary occlusion could be modified. ${ }^{4}$ From these experiments we concluded as follows:

Of greatest interest, from the clinical point of view, is the finding that the severity and extent of myocardial ischemic injury resulting from coronary occlusion could be radically altered not only by pretreatment of the animal but also by an appropriate intervention as late as three hours after the coronary occlusion. This suggests that measures designed for reduction of myocardial oxygen demands and improvement of coronary perfusion, when effected promptly after a patient has been brought to a hospital, might potentially reduce the ultimate size of the infarction.*

$\mathrm{We}^{5}$ also observed that when coronary artery reperfusion was carried out as late as 3 hours after occlusion, there was less pathologic evidence of myocardial necrosis and improved cardiac function than when the occlusion was sustained.

When the fibrinolytic agent streptokinase was purified, investigators began to determine whether this agent administered intravenously might be beneficial in the treatment of patients with acute MI. A major step forward was taken in 1976 by Chazov, Mateeva, and Mazaev, ${ }^{6}$ who demonstrated, using coronary arteriography, that the intracoronary infusion of streptokinase lysed coronary thrombi and restored myocardial reperfusion. Subsequently, we $\mathrm{w}^{7}$ demonstrated, using intracoronary thallium-201 myocardial perfusion scanning, that myocardial tissue actually was salvaged by the timely administration of intracoronary streptokinase.

\footnotetext{
* From Maroko PR, Kjekshus JK, Sobel BE, Watanabe T, Covell JW, Ross J Jr, Braunwald E. Factors influencing infarct size following experimental coronary artery occlusion. Circulation. 1971;43:67-82. Published with the permission of the American Heart Association.
} 


$$
\begin{array}{ll}
\text { Abbreviations and Acronyms } \\
\text { ACS }=\text { acute coronary syndrome } \\
\text { MI }=\text { myocardial infarction } \\
\text { NSTEMI = } & \text { non-ST-elevation myocardial } \\
& \text { infarction } \\
\text { PCI } & =\text { percutaneous coronary intervention } \\
\text { STEMI }= & \text { ST-elevation myocardial } \\
& \text { infarction } \\
\text { TMPG }= & \text { TIMI Myocardial Perfusion } \\
& \text { Grade } \\
\text { tPA } & \text { tissue plasminogen activator }
\end{array}
$$

By the middle 1980s, it was appreciated that for fibrinolytic therapy to be of practical benefit, the drug had to be administered intravenously rather than by the intracoronary route. Relatively few hospitals around the world had catheterization laboratories, and even in those with such facilities it often took hours to assemble the catheterization team, take the patient to the laboratory, and infuse the lytic agent directly into the occluded coronary artery. Also, a more powerful and fibrin-specific lytic agent, produced by recombinant techniques, tissue plasminogen activator (tPA), had been developed. In 1984, the US National Heart, Lung, and Blood Institute established the Thrombolysis in Myocardial Infarction (TIMI) Trial Study Group, a confederation of experienced investigators and well-staffed and equipped coronary care units. One of the authors (E.B.) was asked to chair this group and did so until 2011, when the other (M.S.S.) assumed this role. TIMI has been privileged to have a number of talented senior investigators, including Drs Elliott M. Antman, Christopher P. Cannon, C. Michael Gibson, Robert P. Giugliano, David A. Morrow, Deepak L. Bhatt.

Since its inception, the principal goal of the TIMI Study Group has been to conduct high-quality clinical trials that enhance the care of patients with cardiovascular disease and its risk factors. TIMI has been involved in 57 major studies, which include a wide array of phase I to phase IV trials and registries. These have ranged in size from less than 30 to more than 26,000 subjects. Trials have been conducted in 45 countries and at more than 1000 separate sites. The genesis of a new clinical trial typically involves one of two pathways. In some instances, TIMI identifies an unmet need or unanswered question in cardiovascular therapeutics that we believe can be addressed by studying an existing medication for a new indication. In other cases, a pharmaceutical or biotechnology company will approach us with a drug at preclinical or early-stage clinical development and seek our counsel as to the potential benefit of the drug and how it might best be studied. Inasmuch as our time is our most precious commodity, we carefully vet any potential new trial, benefiting from the collective experience and wisdom of both our investigators and operational staff.

Although the initial TIMI trials focused on fibrinolytic agents, we have also studied antithrombotic, antiplatelet, anti-ischemic, lipid-lowering, and anti-inflammatory agents as well as percutaneous coronary intervention (PCI). Although the first trials involved patients with ST-elevation myocardial infarction (STEMI), we have extended our observations to other types of acute coronary syndrome (ACS), as well as to patients with chronic coronary artery disease, hyperlipidemia, and to the cardiovascular outcomes in patients with diabetes mellitus. In addition, the TIMI Study Group has used its growing database of clinical findings, biomarkers, and genotypes to enhance the understanding of coronary artery disease. An equally important goal has been to train the next generation of clinical investigators. Many of our postdoctoral fellows have assumed important faculty positions at TIMI and elsewhere.

\section{ST-ELEVATION MYOCARDIAL INFARCTION (STEMI)}

The effects of the then-new intravenously administered tPA were compared with streptokinase on coronary and clinical outcome in the TIMI group's first trial. ${ }^{8}$ We observed successful reperfusion of occluded coronary arteries in $62 \%$ of patients who received tPA and $31 \%$ in those who received streptokinase. Patients with a patent artery had a lower mortality at 1 year than did those who did not, leading to what we have termed the "early open artery hypothesis" (Figure 1).

By the middle 1980s, percutaneous transluminal coronary angioplasty had become widely used in the management of severe angina pectoris in patients with stable coronary artery disease, and it was suggested that it might also be useful after fibrinolytic therapy in patients with STEMI. Therefore, in the TIMI 2 trial we compared the clinical outcome in patients who received tPA with either a "late invasive strategy" consisting of coronary arteriography 18 to 48 hours after the onset of symptoms, followed by coronary revascularization if the anatomy was appropriate, or a "conservative strategy," in which coronary arteriography and revascularization were carried out only if recurrent ischemia occurred or a positive electrocardiographic exercise stress test was present before hospital discharge. $\mathrm{We}^{9}$ anticipated that the invasive strategy would lead to improved clinical outcomes, but we observed, in fact, that the incidence of death and recurrent MI was similar in the 2 groups. What we learned from the TIMI 2 trial was that with the catheter-based revascularization techniques of that era (which did not include its performance on an emergency basis or stent implantation), a routine invasive strategy was not necessary so long as it was readily available for post-MI patients with 


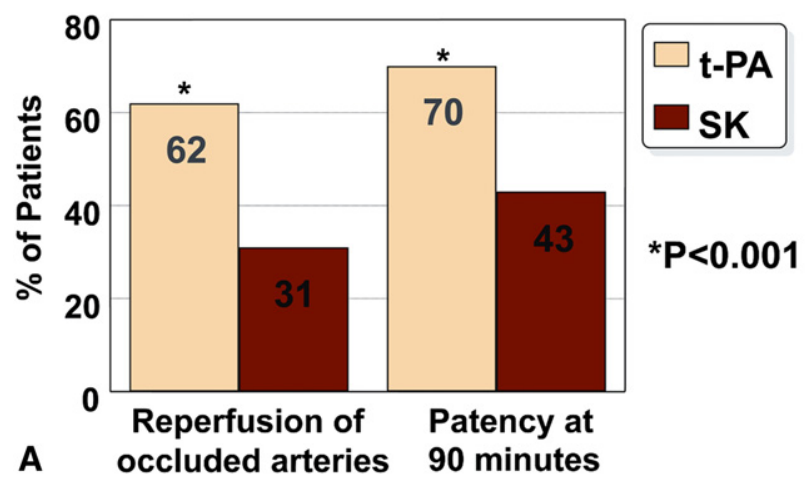

\section{Impact of 90 Minute Patency on Mortality}

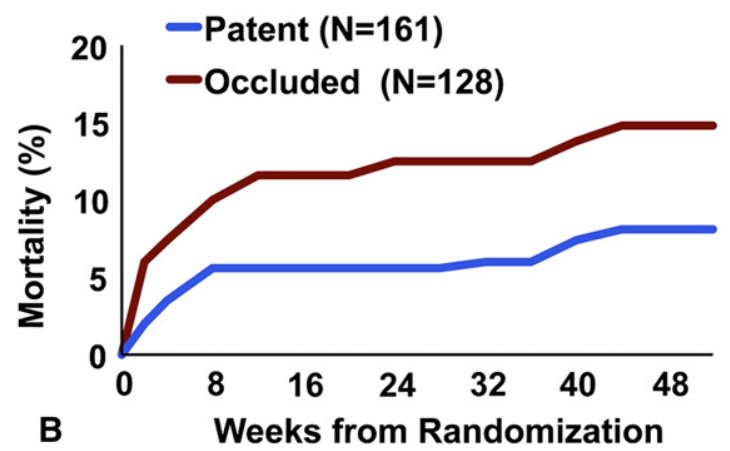

FIGURE 1. The TIMI 1 trial enrolled 290 patients with acute myocardial infarction and randomized them to tissue plasminogen activator ( $t P A)$ or streptokinase (SK). A, Patients treated with tPA (peach bars) had improved reperfusion and vessel patency at 90 minutes. (Data from the TIMI Study Group. ${ }^{8}$ ) B, Regardless of treatment arm, a patent infarct-related artery at 90 minutes was associated with improved long-term survival. [From Dalen J, Gore JM, Braunwald E, Borer J, Goldberg RJ, Passamani ER, et al. Six- and twelve-month follow-up of the Phase I Thrombolysis in Myocardial Infarction (TIMI) trial. Am J Cardiol. 1988;62:179-85.]

spontaneous or induced ischemia. Initially, the conservative approach after fibrinolytic therapy was widely adopted around the world and in rural areas of North America, whereas the invasive approach was used where patients had rapid access to expert percutaneous transluminal coronary angioplasty. At present, urgent primary PCI is used whenever possible.

In the TIMI 2 trial, we also compared early intravenous metoprolol followed by oral administration of this beta-blocker with oral beta-blocker begun on day 6. Early intravenous beta-blockade was associated with statistically significant reductions in reinfarction and in recurrent ischemia. ${ }^{10}$

Four later TIMI trials have examined the effects of adjunctive therapy in STEMI patients.

1. Early Retavase-Thrombolysis in Myocardial Infarction (ER-TIMI 19): By 2000, the critical importance of minimizing the time from the onset of symptoms to the administration of a fibrinolytic or initiating other reperfusion therapy was widely appreciated. Worldwide efforts were undertaken to develop strategies to reduce this time interval. The TIMI 19 trial, led by Dr David A. Morrow, showed that administration of a lytic agent in the ambulance could reduce by one half the time interval from ambulance arrival at the patient to starting a fibrinolytic in the emergency department. ${ }^{11}$ Lytic administration in the ambulance is now rarely applied in North America because of the widespread use of primary PCI and the lack of trained personnel to administer fibrinolytics in the ambulance. However, this approach is widely used in the remainder of the world. Also, radiotelemetry of the electrocardiogram from the ambulance to the receiving hospital, as performed in the TIMI 19 trial, shortens the ultimate "door to balloon time," which has become an important measure of the efficiency of hospital systems in managing patients with STEMI.

2. Enoxaparin and Thrombolysis Reperfusion for Acute Myocardial Infarction Treatment-Thrombolysis in Myocardial Infarction Study 25 (ExTRACT-TIMI 25): Unfractionated heparin had been the antithrombotic
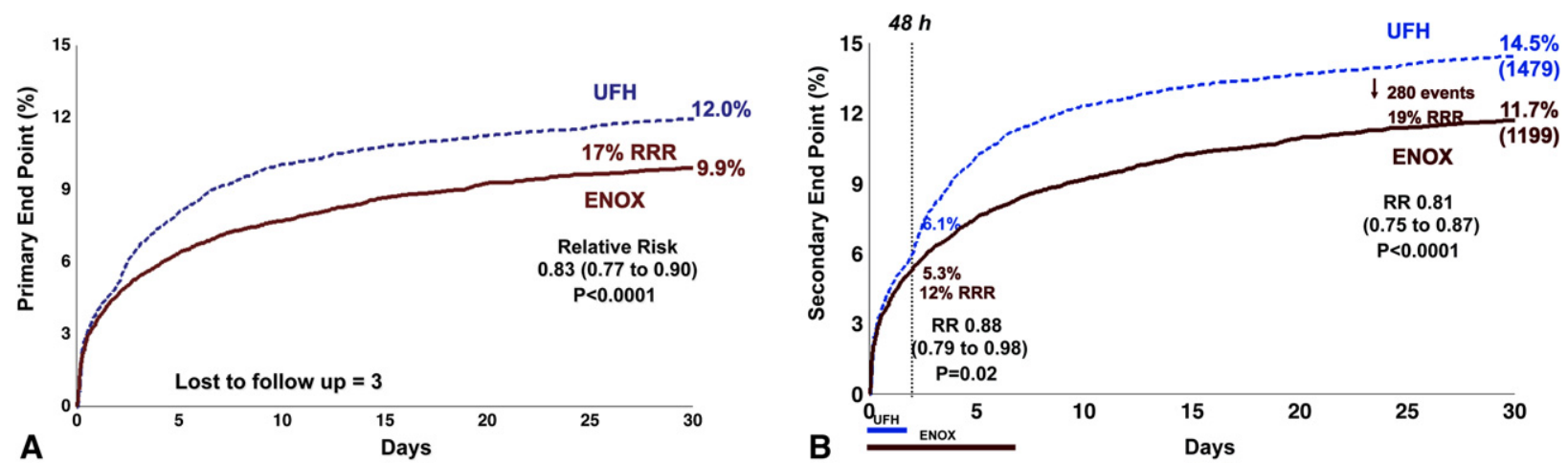

FIGURE 2. Kaplan-Meier curves showing the superiority of enoxaparin (ENOX) over unfractionated heparin $(U F H)$ in the primary (A) and main secondary (B) end points of the ExTRACT-TIMI 25 trial. $^{12} R R$, Relative risk; $R R R$, relative risk reduction. (From Antman et al. ${ }^{12}$ ) 


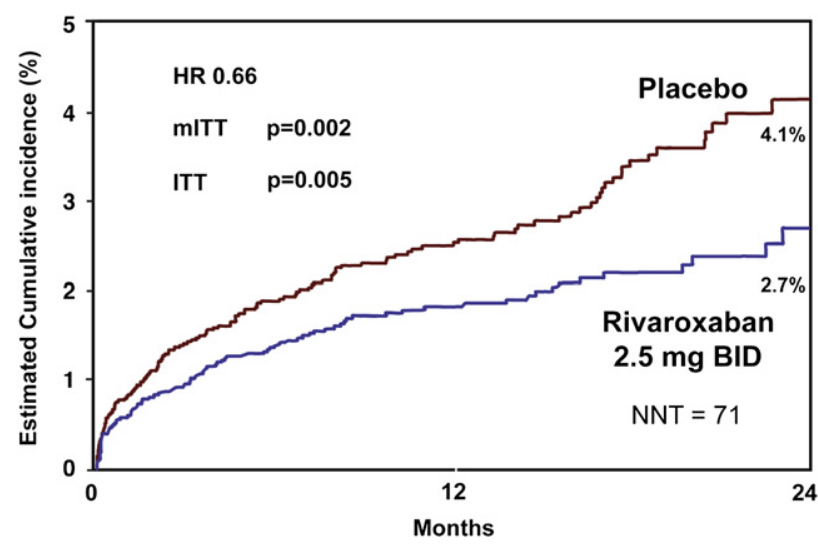

FIGURE 3. Death from cardiovascular causes in placebo and rivaroxaban ( $2.5 \mathrm{mg}$ twice daily) treated patients after acute coronary syndrome in ATLAS-2-TIMI $51 .^{4} H R$, Hazard ratio; BID, twice a day; $N N T$, number needed to treat; $m I T T$, modified intention to treat; ITT, intention to treat. (From Mega et al. ${ }^{14}$ )

drug used almost universally since the earliest days of fibrinolytic therapy to prevent reocclusion after successful lysis. This trial, led by Dr Elliott M. Antman, randomized 20,506 patients with STEMI receiving fibrinolytic therapy to the low molecular weight heparin enoxaparin for the entire period of hospitalization (median, 7 days) or unfractionated heparin for 48 hours. At 30 days' follow-up, enoxaparin significantly reduced the risk of death or MI (the primary end point) by $17 \%$ and reduced the risk of death, MI, or urgent revascularization by $19 \%$ (Figure 2). ${ }^{12}$

3. Clopidogrel as Adjunctive Reperfusion TherapyThrombolysis in Myocardial Infarction 28 (CLARITYTIMI 28): Early in the first decade of this century, increasing attention was directed to the important role of platelets in precipitating acute coronary events. This trial, led by one of the present authors (M.S.S.) and Dr Christopher P. Cannon, enrolled patients with STEMI receiving fibrinolytic therapy and aspirin and randomized them to adjunctive clopidogrel or placebo. The addition of clopidogrel significantly improved infarct-related artery patency and reduced the odds of adverse cardiovascular events. ${ }^{13}$

4. Anti-Xa Therapy to Lower Cardiovascular Events in Addition to Standard Therapy in Subjects With Acute Coronary Syndrome-Thrombolysis in Myocardial Infarction 51 (ATLAS-2-TIMI 51): The contemporary treatment of STEMI includes urgent coronary arteriography followed immediately by stenting if the anatomy is suitable. Stent thrombosis is largely prevented by the administration of aspirin and clopidogrel (or other P2 $\mathrm{Y}_{12}$ platelet receptor blockers). The ATLAS-2-TIMI 51 trial randomized 15,526 patients with an ACS, one half of whom had STEMI (and other forms of ACS),
Death, MI, Rehosp for ACS at 6 Months

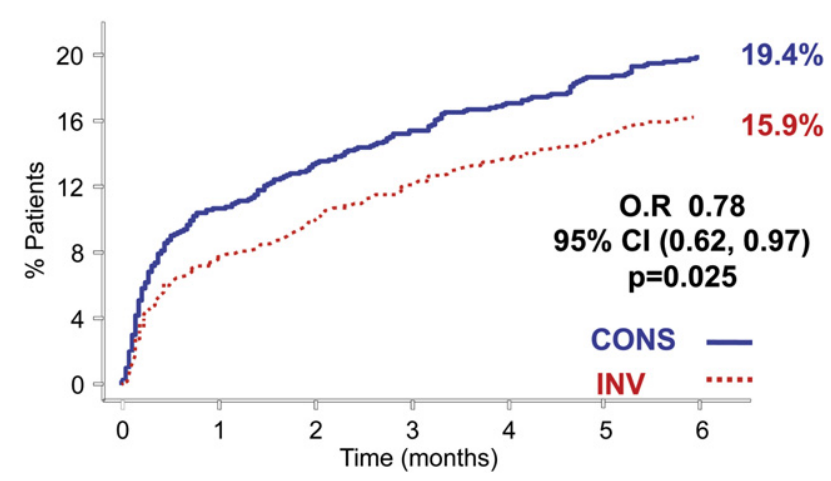

FIGURE 4. TACTICS-TIMI 18 randomized 2220 patients with unstable angina or non-ST elevation myocardial infarction to an early invasive strategy (INV) or conservative (CONS) strategy. MI, Myocardial infarction; $A C S$, acute coronary syndrome; $O R$, odds ratio; $C I$, confidence interval. (From Cannon et al. ${ }^{16}$ )

to placebo or 1 of 2 doses of the factor Xa inhibitor, rivaroxaban, begun an average of 4.7 days after the onset of ACS (Figure 3). The very low dose $(2.5 \mathrm{mg}$ bid) resulted in a $34 \%$ reduction in cardiovascular death (and a $33 \%$ reduction in all-cause death) after treatment for an average of 2 years. ${ }^{14}$ The $5-\mathrm{mg}$ bid dose did not have this salutary effect. These findings open the door to adding a very low dose of an anticoagulant to dual antiplatelet therapy in ACS.

\section{NON-ST-ELEVATION ACS (NSTE-ACS)}

Given the enormous and growing prevalence of NSTEACS, that is, unstable angina and non-STEMI, the TIMI Study Group has focused increasingly on this syndrome. The addition of intravenous tPA to standard therapy in the TIMI 3 trial did not improve outcome in this condition, ${ }^{15}$ an important negative trial inasmuch as many of these patients were receiving fibrinolytic therapy at the time. In the Treat Angina With Aggrastat and Determine Cost of Therapy With an Invasive or Conservative Strategy (TACTICS-TIMI 18) trial, led by Dr Christopher P. Cannon, an invasive strategy consisting of coronary arteriography followed by revascularization if the anatomy was suitable, was compared with a more conservative strategy in which catheterization was carried out only if the patient experienced recurrent ischemia or exhibited a positive stress test. ${ }^{16} \mathrm{We}$ observed a significant $22 \%$ reduction in the odds of the primary end point of death, MI, or rehospitalization in patients randomized to the invasive strategy at 6 months (Figure 4).

We also compared the low molecular weight heparin enoxaparin with unfractionated heparin in 3910 patients with NSTE-ACS in the TIMI 11 trial, ${ }^{17}$ which was led by Dr Elliott M. Antman. As in the EXTRACT-TIMI 25 trial, enoxaparin significantly reduced the risk of death, MI, or 
Balance of Efficacy and Safety

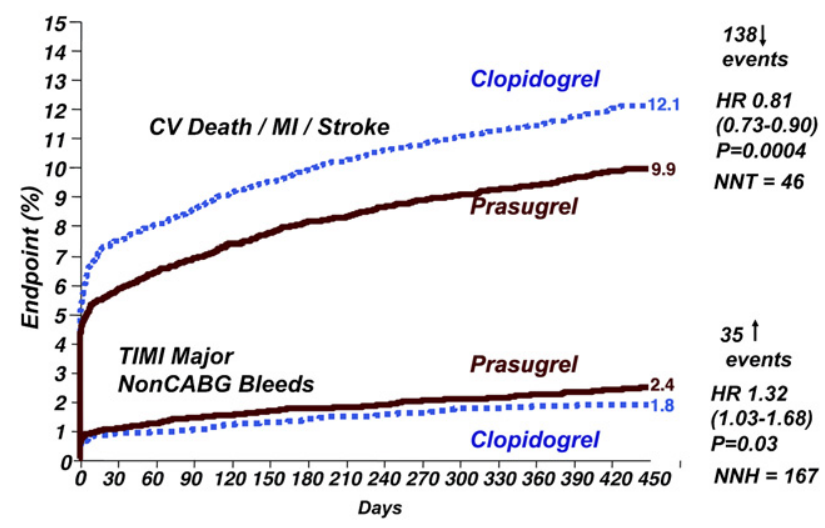

FIGURE 5. TRITON-TIMI 38 randomized 13,608 patients with acute coronary syndrome undergoing percutaneous coronary intervention to prasugrel or clopidogrel. $H R$, Hazard ratio; $C V$, cardiovascular; $M I$, myocardial infarction; $C A B G$, coronary artery bypass graft; $N N T$, number needed to treat; $N N H$, number needed to harm; TIMI, Thrombolysis in Myocardial Infarction. (From Wiviott et al. ${ }^{18}$ )

urgent revascularization at 8 and 14 days. On the basis of this and other trials, low molecular weight heparin is now widely used around the world in patients with NSTE-ACS.

Inasmuch as platelets play an important role in the pathogenesis of ACS, the combination of 2 antiplatelet agents, aspirin and the second-generation thienopyridine, clopidogrel, have become central in the treatment of this condition. In the Trial to Assess Improvement in Therapeutic Outcomes by Optimizing Platelet Inhibition With PrasugrelThrombolysisin Myocardial Infarction 38 (TRITON-TIMI 38) trial, led by Dr Antman and Dr Stephen D. Wiviott,

\section{Stent Thrombosis} (ARC Definite + Probable)

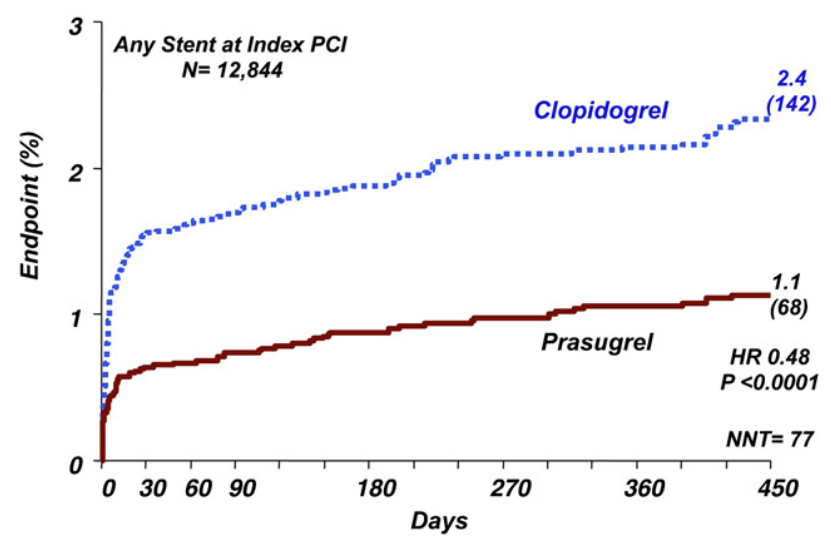

FIGURE 6. In TRITON-TIMI 38 , subjects randomized to prasugrel had a significant $52 \%$ reduction in the risk of stent thrombosis compared with clopidogrel. This benefit was seen for both drug-eluting and baremetal stents. ARC, Academic Research Consortium; PCI, percutaneous coronary intervention; $H R$, hazard ratio; $N N T$, number needed to treat. (Modified from Wiviott et al. ${ }^{19}$ ) a third-generation thienopyridine, prasugrel, more powerful than clopidogrel, was compared with clopidogrel in 13,608 patients with ACS undergoing PCI. ${ }^{18}$ Prasugrel significantly reduced the risk of the primary end point, that is, death, MI, or stroke, by $19 \%$ (Figure 5) and stent thrombosis by $52 \%{ }^{19}$ (Figure 6 ). However, prasugrel significantly increased the risk of major bleeding and, in patients with prior stroke and transient ischemic attack, intracranial bleeding. Patients with diabetes mellitus exhibited a particular benefit with prasugrel compared with clopidogrel without a significant increase in major bleeding. ${ }^{20}$

We compared ranolazine, a piperazine novel antiischemic drug, with placebo on 6560 patients in the Metabolic Efficiency With Ranolazine for Less Ischemia in Non-ST-Elevation Acute Coronary Syndromes-Thrombolysis in Myocardial Infarction 36 (MERLIN-TIMI 36) trial, led by Dr David A. Morrow. ${ }^{21}$ Although ranolazine did not significantly reduce the risk of the composite end point of cardiovascular death, MI, or recurrent ischemia, it significantly reduced the risk of recurrent ischemia, supporting its use as an anti-ischemic drug. Furthermore, ranolazine had a favorable safety profile and significantly reduced the incidence of ventricular tachycardia as recorded on a Holter monitor by $37 \%{ }^{22}$ and proved also to be a moderately effective antidiabetic agent. ${ }^{23}$

\section{CHRONIC ATHEROSCLEROTIC DISEASE}

Although aspirin is strongly indicated in patients after MI, it is not clear whether platelet inhibition through

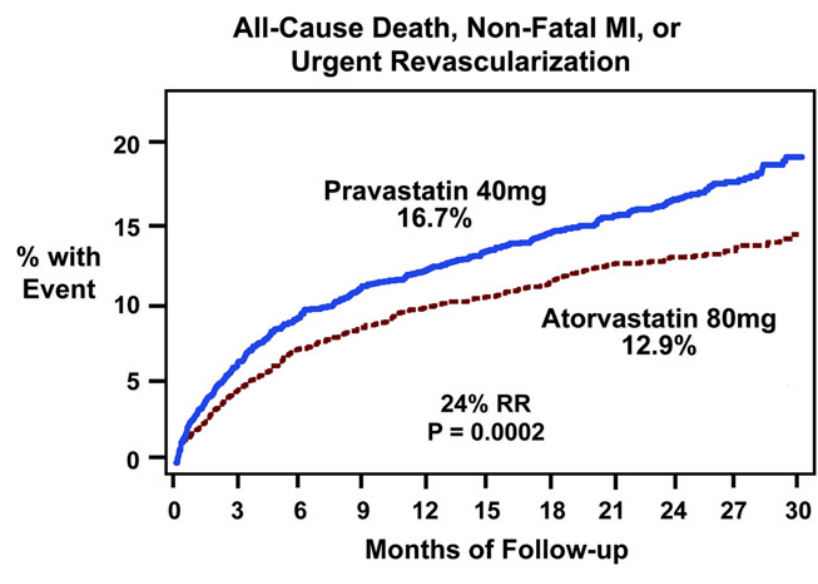

FIGURE 7. Comparison of intensive and standard lipid-lowering therapy with statins after an acute coronary syndrome. After acute coronary syndrome, intensive lipid-lowering therapy with a high-potency statin significantly reduced the risk of adverse outcomes as compared with moderate-potency statin therapy. $M I$, Myocardial infarction; $R R$, relative risk. (From Ray KK, Cannon CP, McCabe CH, Cairns R, Tonkin AM, Sacks FM, et al. Early and late benefits of high-dose atorvastatin in patients with acute coronary syndromes. Results from the PROVE IT-TIMI 22 trial. $J$ Am Coll Cardiol. 2005;46:1405-10. Published with permission of the American College of Cardiology Foundation.) 
another mechanism is beneficial. In the Thrombin Receptor Antognist in Secondary Prevention of Atherosclerotic Ischemic Events-Thrombolysis in Myocardial Infarction 50 (TRA 2P-TIMI 50) trial, led by Dr David A. Morrow, we compared vorapaxar, a potent protease-activated receptor1 platelet receptor inhibitor that blocks the platelet thrombin receptor, with placebo in 26,449 patients with stable atherosclerosis. Overall, there was a significant reduction in the primary end point of cardiovascular death, MI, or stroke that appeared to be most robust in patients with prior MI. In contrast, there was little or no benefit and an excess of intracranial bleeding in stroke patients. ${ }^{24}$

\section{CHOLESTEROL LOWERING}

TIMI has been involved in studying the effects of lowering cholesterol. The Pravastatin or Atorvastatin Evaluation and Infection Therapy-Thrombolysis in Myocardial Infarction 22 (PROVE IT-TIMI 22) trial in patients after ACS, led by Dr Christopher P. Cannon, studied the effects of what was at the time (2001) considered to be extreme lowering of low-density lipoprotein cholesterol. ${ }^{25}$ In this trial, 4162 post-ACS patients were randomized to intensive statin therapy (atorvastatin $80 \mathrm{mg}$ daily) or standard statin therapy (pravastatin $40 \mathrm{mg}$ daily). Intensive lipid lowering to a mean of $62 \mathrm{mg} / \mathrm{dL}$ significantly reduced the risk of death, MI, or urgent revascularization by $24 \%$ when compared with standard therapy, which reduced low-density lipoprotein cholesterol to $95 \mathrm{mg} / \mathrm{dL}$. This benefit of more intensive lipid lowering with atorvastatin appeared within the first month of starting therapy ${ }^{26}$ (Figure 7). This trial remains one of our favorites for several reasons: the trial demonstrated an unequivocal benefit; the findings were incorporated into practice guidelines and easily implemented by clinicians; a wealth of secondary clinical, biomarker, and genetic analyses have emanated from the trial database;

\section{TIMI Risk Score for UA/NSTEMI}

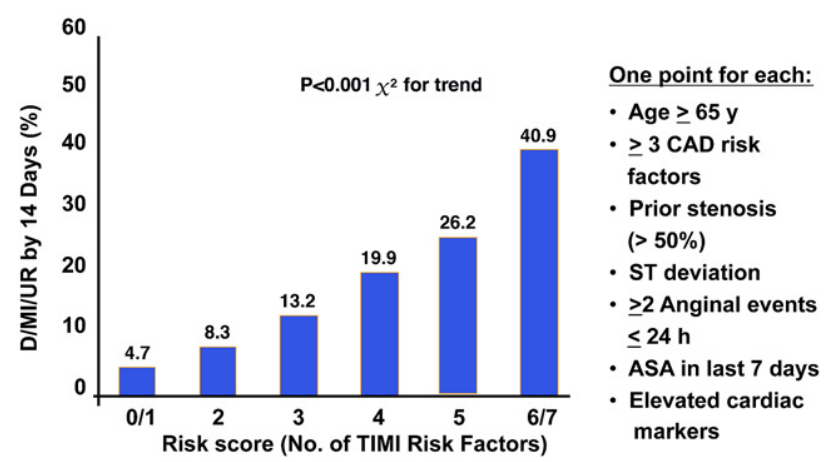

FIGURE 8. The TIMI Risk Score for unstable angina (UA) and non-STsegment elevation myocardial infarction (NSTEMI) is a simple prognostication scheme that categorizes a patient's risk of death and ischemic events. $C A D$, Coronary artery disease; $D / M I / U R$, death, myocardial infarction, urgent revascularization; ASA, aspirin; TIMI, Thrombolysis in Myocardial Infarction. (From Antman et al. ${ }^{27}$ )
TIMI Risk Score for STEM

DERIVATION SET: InTIME ॥

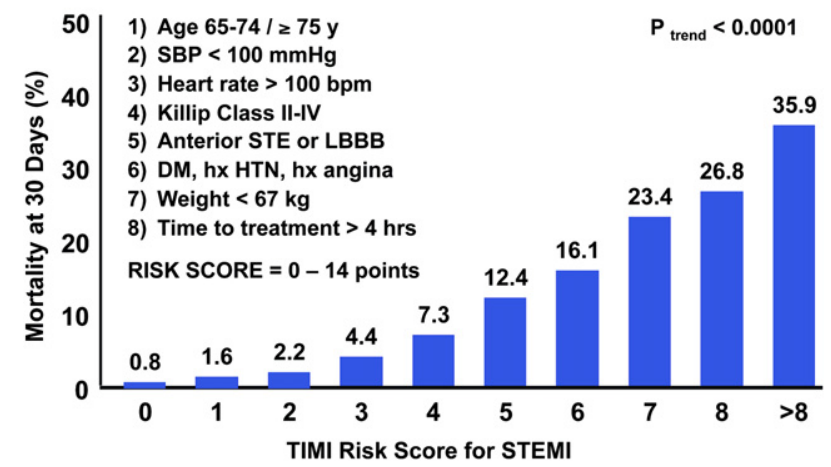

FIGURE 9. TRS, TIMI Risk Score for ST-elevation myocardial infarction. $S B P$, Systolic blood pressure; $D M$, diabetes mellitus; $H T N$, hypertension; $\angle B B B$, left bundle branch block; STEMI, ST-elevation myocardial infarction; TIMI, Thrombolysis in Myocardial Infarction. (From Marrow et al. ${ }^{28}$ )

and, like any good experiment, the data have generated new hypotheses to test in terms of further cholesterol reduction (see "Ongoing TIMI Trials") and the role of inflammation in cardiovascular disease.

\section{TIMI RISK SCORES}

The TIMI Study Group has used its large database to establish clinical scores for risk stratification. The TIMI Risk Score for NSTEMI-ACS is a simple 7-point scale that categorizes a patient's risk of death and ischemic events and provides a basis for therapeutic decision making ${ }^{27}$ (Figure 8). This score was derived in TIMI 11B and was subsequently validated in several trials. The TIMI Risk Score for STEMI consists of a 14-point scale based on the history, physical examination, and presentation ${ }^{28}$ (Figure 9). The TIMI Risk Index is a simple index and is based on a combination of age, heart rate, and systolic arterial pressure at presentation, characteristics that are easily assessed by nonphysicians in patients with STEMI. Every 5 -point increase is associated with a $43 \%$ increase in 30-day mortality. The index was derived from the Intravenous NPA for the Treatment of Infarcting Myocardium Early-Thrombolysis in Myocardial Infarction 17 (InTIME 2-TIMI 17) trial and validated in TIMI 9 and 25 as well as in the National Registry of Myocardial Infarction. ${ }^{29}$

The TIMI Coronary Flow Grade, established in the TIMI 1 trial, was designed to assess epicardial perfusion at angiography. ${ }^{8}$ It is scored from 0 to 3, with TIMI Flow Grade 0 representing a total occlusion and TIMI Flow Grade 3 representing normal epicardial perfusion. The TIMI Flow Grade is a powerful predictor of clinical outcome (Figure 10); its value has been confirmed in many trials and it is now universally used. The number of cineangiographic frames required for contrast medium to reach a standardized distal landmark after injection into a proximal 


\section{TIMI Flow Grade}

\section{TIMI 0 Complete occlusion \\ TIMI 1 Penetration of obstruction by contrast but no distal perfusion \\ TIMI 2 Perfusion of entire artery but delayed flow}

TIMI 3 Full perfusion, normal flow

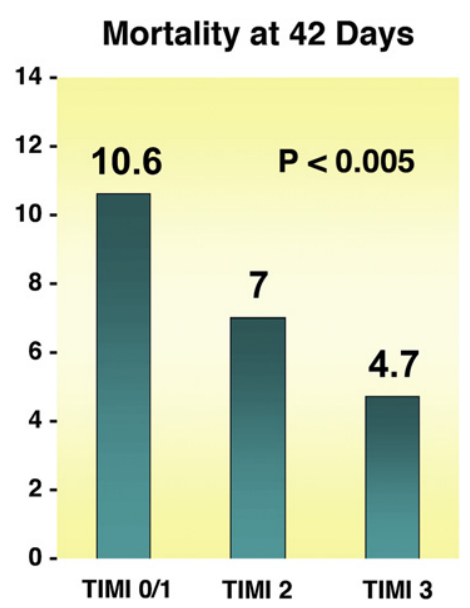

FIGURE 10. TIMI Flow Grade is scored from 0 to 3 . It is a powerful predictor of outcome. Here shown are the findings from the TIMI 1 trial. TIMI, Thrombolysis in Myocardial Infarction. [Data from Flyngenring BP, Sheehan FH, Kennedy JW, Dodge HT, Braunwald E. Does arterial patency 90 minutes following thrombolytic therapy predict 42 day survival? J Am Coll Cardiol. 1991;17(Suppl A):275A.]

coronary artery, termed the TIMI Frame Count, was established by Dr C. Michael Gibson to enhance reproducibility of the angiographic assessment of coronary blood flow. The risk of adverse clinical outcomes rises proportionately with an increased frame count. ${ }^{30}$

The TIMI Myocardial Perfusion Grade (TMPG), also developed by Dr Gibson, assesses microvascular perfusion of the portion of the left ventricle in the area of distribution of the culprit artery. ${ }^{31}$ It is scored from 0 to 3 with TMPG 0 representing no apparent tissue-level perfusion and TMPG 3 indicating normal perfusion. It too has been found to be an independent predictor of clinical outcome.

\section{BIOMARKERS}

The TIMI Group has had a strong interest in biomarkers because of their ability to improve risk stratification. This effort is led by Dr David A. Morrow. In the TIMI 3 trial in patients with NSTEMI, ${ }^{32}$ patients with a serum troponin greater than $9 \mathrm{ng} / \mathrm{mL}$ had a 7.5 -fold higher risk of death than patients with a troponin less than $0.4 \mathrm{ng} / \mathrm{mL}$. In TACTICSTIMI 18, patients with an elevated troponin at baseline appeared to derive a greater treatment benefit with an early invasive strategy, as compared with patients without a troponin elevation. ${ }^{33}$

In Orbofiban in Patients with Unstable Coronary Syndromes-Thrombolysis in Myocardial Infarction 16 (OPUS-TIMI 16), elevated levels of B-type natriuretic peptide were associated with an increased risk of death, an observation that was confirmed in the Aggrastat to ZocorTIMI 21 (A to Z-TIMI 21) trial. ${ }^{34}$

Three independent biomarkers (troponin, C-reactive protein, and B-type natriuretic peptide) were obtained on admission in a multimarker strategy devised by Dr Marc S. Sabatine. One point was assigned for each biomarker that was abnormally elevated (troponin I $>0.1 \mathrm{mg} / \mathrm{mL}$,
C-reactive protein $>1.5 \mathrm{mg} / \mathrm{dL}$, and B-type natriuretic peptide $>80 \mathrm{pg} / \mathrm{mL}$ ). The relative risk rose progressively with the number of elevated biomarkers. ${ }^{35}$

\section{PHARMACOGENETICS}

Over the past several years, the TIMI Study Group has delved into pharmacogenetics. Efforts led by M.S.S. and Dr Jessica L. Mega demonstrated that approximately $30 \%$ of individuals harbor a loss-of-function allele in the CYP2C19 gene that results in lower levels of the active clopidogrel metabolite, lesser degrees of platelet inhibition, and, using patients from TRITON-TIMI 38 with an ACS

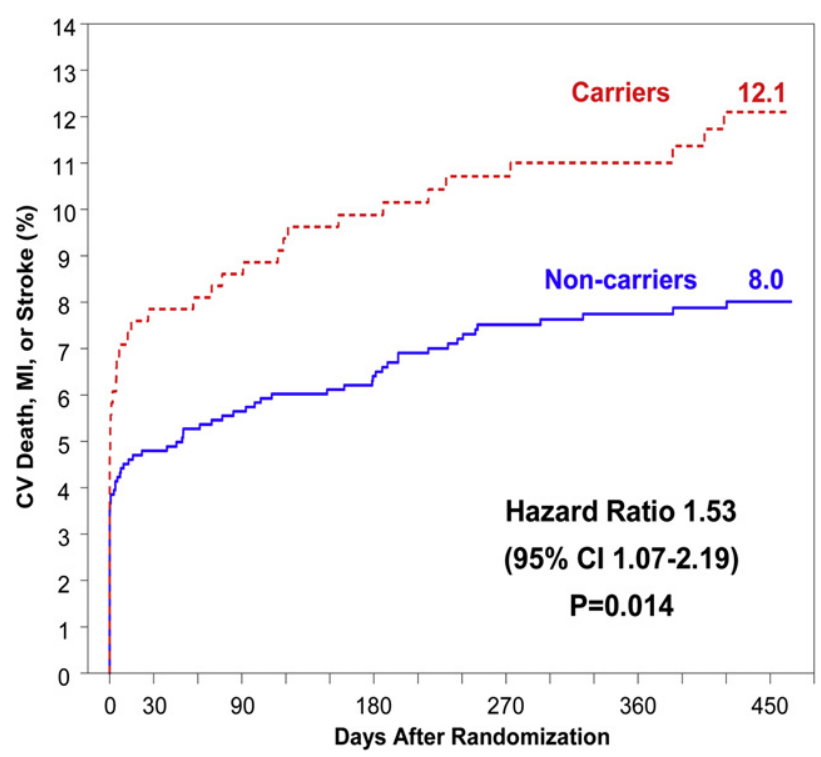

FIGURE 11. Efficacy outcomes (cardiovascular [CV] death, myocardial infarction [MI], and stroke) among carriers of the CYP2C19 reduced function allele in clopidogrel-treated patients in the TIMI 38 trial. CI, Confidence interval. (From Mega et al. ${ }^{36}$ ) 
and planned PCI, approximately $50 \%$ higher risk of cardiovascular death, MI, or stroke, and more than a threefold increased risk of stent thrombosis ${ }^{36}$ (Figure 11).

The subsequent Escalating Clopidogrel by Involving a Genetic Strategy-Thrombolysis in Myocardial Infarction 56 (ELEVATE-TIMI 56) trial, led by Dr Mega, demonstrated that it requires tripling the daily maintenance dose of clopidogrel to achieve platelet inhibition equivalent to that seen with the standard clopidogrel maintenance dose in wild-type individuals. ${ }^{37}$

\section{ONGOING TIMI TRIALS}

The TIMI Study Group is currently conducting 7 largescale multinational, multicenter trials. Improved Reduction of Outcomes: Vytorin Efficacy International Trial-Thrombolysis in Myocardial Infarction 40 (IMPROVE IT-TIMI 40), led by Drs Cannon and Giugliano, and conducted in collaboration with the Duke Clinical Research Institute, is a randomized, double-blind trial designed to assess the possible benefit of treating more than 18,000 patients stabilized after ACS to low-density lipoprotein cholesterol goals that are even lower than those targeted in PROVE IT-TIMI 22 , using a combination of simvastatin and ezetimibe. ${ }^{38}$ The ENGAGE-TIMI 48 trial, led by Drs Antman and Giugliano, is comparing the novel factor $\mathrm{Xa}$ antagonist edoxaban with warfarin in 20,500 patients with atrial fibrillation to look at the incidence of systemic embolism, stroke and bleeding. ${ }^{39}$

The Stabilization of Plaques Using Darapladib-Thrombolysis in Myocardial Infarction 52 (SOLID-TIMI 52) trial, led by Dr Cannon, is studying the effects of the lipoproteinPLA2 antagonist darapladib in 13,500 patients after ACS. ${ }^{40}$ The Saxagliptin Assessment of Vascular Outcomes Recorded in Patients With Diabetes Mellitus-Thrombolysis in Myocardial Infarction 53 (SAVOR-TIMI 53) trial is studying the effects of the DPP4 inhibitor saxagliptin on cardiovascular outcomes in 16,500 patients with type 2 diabetes. $^{41}$ The PEGASUS-TIMI 54 trial, led by M.S.S., is studying the effects of adding ticagrelor, a reversible $\mathrm{P}_{2} \mathrm{Y}_{12}$ platelet receptor antagonist, to aspirin in patients 1 to 3 years after MI. The Randomized Evaluation of the Effects of Anacetrapib Through Lipid-ModificationThrombolysis in Myocardial Infarction 55 (REVEAL Hps-3-TIMI 55) trial, carried out in collaboration with the Clinical Trial Service Unit at the University of Oxford, is studying the cholesterol ester transport protein inhibitor anacetrapib in 30,000 patients with chronic coronary artery disease. This drug raises high-density lipoprotein cholesterol and reduces low-density lipoprotein cholesterol. The LDL-C Assessment With PCSK9 Monoclonal Antibody Inhibition Combined With Statin Therapy-Thrombolysis (LAPLACE-TIMI 57) trial, led by M.S.S., is studying the effects of a potent new inhibitor of PCSK-9 on low-density lipoprotein cholesterol concentration in patients with hypercholesterolemia. ${ }^{42}$

\section{References}

1. Tennant R, Wiggers CJ. The effect of coronary occlusion on myocardial contraction. Am J Physiol. 1935;112:351-61.

2. Blumgart HL, Gilligan R, Schlesinger MJ. Experimental studies on the effect of temporary occlusion of coronary arteries. II. The production of myocardial infarction. Am Heart J. 1941;22:374-89.

3. Braunwald E, Covell JW, Maroko PR, Ross J Jr. Effect of drugs and of counterpulsation on myocardial oxygen consumption. Circulation. 1969;40(Suppl IV): 220-8.

4. Maroko PR, Kjekshus JK, Sobel BE, Watanabe T, Covell JW, Ross J Jr, et al. Factors influencing infarct size following experimental coronary artery occlusion. Circulation. 1971;43:67-82.

5. Maroko PR, Braunwald E. Modification of myocardial infarction size after coronary occlusion. Ann Intern Med. 1973;79:720-33.

6. Chazov EI, Mateeva LS, Mazaev AV. Intracoronary administration of fibrinolysin in acute myocardial infarction. Ter Arkh. 1976;48:8-19.

7. Markis JE, Malagold M, Parker JA, Silverman KJ, Barry WH, Als AV, et al. Myocardial salvage after intracoronary thrombolysis with streptokinase in acute myocardial infarction: assessment of intracoronary thallium-201. N Engl J Med 1981;305:777-82.

8. The TIMI Study Group. Braunwald E (Chairman). The Thrombolysis in Myocardial Infarction (TIMI) trial. Phase I findings. N Engl J Med. 1985;312:932-6.

9. The TIMI Study Group. Braunwald E (Chairman): Comparison of invasive and conservative strategies after treatment with intravenous tissue plasminogen activator in acute myocardial infarction. Results of the Thrombolysis in Myocardial Infarction (TIMI) Phase II Trial. N Engl J Med. 1989;320:618-27.

10. Roberts R, Rogers WJ, Mueller HS, Lambrew CT, Diver DJ, Smith HC, et al Immediate versus deferred $\beta$-blockade following thrombolytic therapy in patients with acute myocardial infarction: results of the Thrombolysis in Myocardial Infarction (TIMI) II-B Study. Circulation. 1991;83:422-37.

11. Morrow DA, Antman EM, Sayah A, Schuhwerk KC, Giugliano RP deLemos JA, et al. Evaluation of the time saved by prehospital initiation of reteplase for ST-elevation MI: results of The Early Retavase-Thrombolysis in Myocardial Infarction (ER-TIMI) 19 trial. J Am Coll Cardiol. 2002;40: 71-7.

12. Antman EM, Morrow DA, McCabe CH, Murphy SA, Ruda M, Sadowski Z, et al Enoxaparin versus unfractionated heparin with fibrinolysis for ST-elevation myocardial infarction. N Engl J Med. 2006;354:1477-88.

13. Sabatine MS, Cannon CP, Gibson CM, Lopez-Sendon JL, Montalescot G Theroux P, et al. Addition of clopidogrel to aspirin and fibrinolytic therapy for myocardial infarction with ST-segment elevation. N Engl J Med. 2005;352: 1179-89.

14. Mega JL, Braunwald E, Wiviott SD, Bassand J-P, Bhatt DL, Bode C, et al. Rivaroxaban in patients with a recent acute coronary syndrome. N Engl J Med. 2012; 366:54-63.

15. The TIMI III B Investigators. Braunwald E. (Chairman): Effects of tissue plasminogen activator and a comparison of early invasive and conservative strategies in unstable angina and non-q-wave myocardial infarction. Results of the TIMI III B Trial. Circulation. 1994;89:1545-56.

16. Cannon CP, Weintraub WS, Demopoulos LA, Vicari R, Frey MJ, Lakkis N, et al Comparison of early invasive and conservative strategies in patients with unstable coronary syndromes treated with the glycoprotein IIb/IIIa inhibitor tirofiban. N Engl J Med. 2001;344:1879-87.

17. Antman EM, McCabe CH, Gurfinkel EP, Turpie AGG, Bernink PJLM, Salein D et al. Enoxaparin prevents death and cardiac ischemic events in unstable angina/ non-Q-wave myocardial infarction: results of the Thrombolysis in Myocardial Infarction (TIMI) 11B Trial. Circulation. 1999;100:1593-601.

18. Wiviott SD, Braunwald E, McCabe CH, Montalescot G, Ruzyllo W, Gottlieb S et al. Prasugrel versus clopidogrel in patients with acute coronary syndromes. N Engl J Med. 2007;357:2001-5.

19. Wiviott SD, Braunwald E, McCabe CH, Horvath I, Keltai M, Herrman JP, et al. Intensive oral antiplatelet therapy for reduction of ischemic events including stent thrombosis in patients with acute coronary syndromes treated with percutaneous coronary intervention and stenting in the TRITON-TIMI 38 trial: a subanalysis of a randomized trial. Lancet. 2008;371:1353-63.

20. Wiviott SD, Braunwald E, Angiolillo DJ, Meisel S, Dalby AJ, Verheugt FWA et al. Greater clinical benefit of more intensive oral antiplatelet therapy with 
prasugrel in patients with diabetes mellitus in the Trial to Assess Improvement in Therapeutic Outcomes by Optimizing Platelet Inhibition with PrasugrelThrombolysis in Myocardial Infarction 38. Circulation. 2008;118:1626-36.

21. Morrow DA, Scirica BM, Karwatowska-Prokopczuk E, Murphy SA, Budaj A, Varshavsky S, et al. Effects of ranolazine on recurrent cardiovascular events in patients with non-ST-elevation acute coronary syndromes. The MERLIN-TIMI 36 randomized trial. JAMA. 2007;297:1775-83.

22. Scirica BM, Morrow DA, Hod H, Murphy SA, Belardinelli L, Hedgepeth CM, et al. Effect of ranolazine, an antianginal agent with novel electrophysiological properties, on the incidence of arrhythmias in patients with non-ST-segmentelevation acute coronary syndrome: results from the Metabolic Efficiency with Ranolazine for Less Ischemia in Non-ST-Elevation Acute Coronary Syndrome Thrombolysis in Myocardial Infarction 36 (MERLIN-TIMI 36) randomized controlled trial. Circulation. 2007;116:1647-52.

23. Morrow DA, Scirica BM, Chaitman BR, McGuire DK, Murphy SA, Karwatowska-Prokopczuk E, et al. Evaluation of glycometabolic effects of ranolazine in patients with and without diabetes mellitus in the MERLIN-TIMI 36 randomized controlled trial. Circulation. 2009;119:2032-9.

24. Morrow DA, Braunwald E, Bonaca MP, Ameriso SF, Dalby AJ, Fish MP, et al. Vorapaxar in the secondary prevention of atherothrombotic events. $N$ Engl J Med. 2012;366:1404-13.

25. Cannon CP, Braunwald E, McCabe CH, Rader DJ, Rouleau JL, Belder R, et al. Intensive versus moderate lipid lowering with statins after acute coronary syndromes. N Engl J Med. 2004;350:1495-504.

26. Ray KK, Cannon CP, McCabe CH, Cairns R, Tonkin AM, Sacks FM, et al. Early and late benefits of high-dose atorvastatin in patients with acute coronary syndromes. Results from the PROVE IT-TIMI 22 trial. J Am Coll Cardiol. 2005; 46:1405-10.

27. Antman EM, Cohen M, Bernink PJLM, McCabe $\mathrm{CH}$, Horacek $\mathrm{T}$, Papuchis G, et al. The TIMI risk score for unstable angina/non-ST elevation MI: a method for prognostication and therapeutic decision making. JAMA. 2000;284:835-42.

28. Morrow DA, Antman EM, Charlesworth A, Cairns R, Murphy SA, deLemos JA, et al. TIMI risk score for ST-elevation myocardial infarction. A convenient, bedside, clinical score for risk assessment at presentation. An Intravenous nPA for Treatment of infracting Myocardium Early II Trial substudy. Circulation. 2000;102:2031-7.

29. Morrow DA, Antman EM, Giugliano RP, Cairns R, Charlesworth A, Murphy SA, et al. A simple risk index for rapid initial triage of patients with ST elevation myocardial infarction: An InTIME II Substudy. Lancet. 2001;358:1571-5.

30. Gibson CM, Murphy SA, Rizzo MJ, Ryan KA, Marble SJ, McCabe CH, et al. Relationship between TIMI frame count and clinical outcomes after thrombolytic administration. Circulation. 1999;99:1945-50.

31. Gibson CM, Cannon CP, Murphy SA, Ryan KA, Mesley R, Marble SJ, et al. Relationship of TIMI myocardial perfusion grade to mortality after administration of thrombolytic drugs. Circulation. 2000;101:125-30.
32. Antman EM, Tanasijevic MJ, Thompson B, Schactman M, McCabe CH, Cannon CP, et al. Cardiac-specific troponin I levels to predict the risk of mortality in patients with acute coronary syndromes. N Engl J Med. 1996;335: 1342-9.

33. Morrow DA, Cannon CP, Rifai N, Frey MJ, Vicari R, Lakkis N, et al. Ability of minor elevations of troponins I and $\mathrm{T}$ to predict benefit from an early invasive strategy in patients with unstable angina and non-ST elevation myocardial infarction. Results from a randomized trial. JAMA. 2001;286:2405-12.

34. de Lemos JA, Morrow DA, Bentey JH, Omland T, Sabatine MS, McCabe CH, et al. The prognostic value of B-type natriuretic peptide in patients with acute coronary syndromes. N Engl J Med. 2001;345:1014-21.

35. Sabatine MS, Morrow DA, de Lemos JA, Gibson CM, Murphy SA, Rifai N, et al. Multimarker approach to risk stratification in non-ST elevation acute coronary syndromes: simultaneous assessment of troponin I, C-reactive protein, and B-type natriuretic peptide. Circulation. 2002;105:1760-3.

36. Mega JL, Close SL, Wiviott SD, Shen L, Hockett RD, Brandt JT, et al. Cytochrome P-450 polymorphisms and response to clopidogrel. $N$ Engl J Med. 2009;360:354-62.

37. Mega JL, Hochholzer W, Frelinger AL 3rd, Kluk MJ, Angiolillo DJ, Kereiakes DJ, et al. Dosing clopidogrel based on CYP2C19 genotype and the effect on platelet reactivity in patients with stable cardiovascular disease. JAMA. 2011;306:2221-8

38. Cannon CP, Giugliano RP, Blazing MA, Harrington RA, Peterson JL, Sisk CM, et al. Design and rationale of IMPROVE-IT (IMProved Reduction of Outcomes: Vytorin Efficacy International Trial): comparison of ezetimbe/simvastatin versus simvastatin monotherapy on cardiovascular outcomes in patients with acute coronary syndromes. Am Heart J. 2008;156:826-32.

39. Ruff CT, Giugliano RP, Antman E, Crugnale SE, Bocanegra T, Mercuri M, et al. Evaluation of the novel factor Xa inhibitor edoxaban compared with warfarin in patients with atrial fibrillation: design and rationale for the Effective aNticoaGulation with factor xA next Generation in atrial fibrillation-Thrombolysis in Myocardial Infarction study 48 (ENGAGE AF-TIMI 48). Am Heart J. 2010;160: 635-41.

40. O’Donoghue ML, Braunwald E, White HD, Serruys P, Steg G, Hochman J, et al. Study design and rationale for the Stabliization of pLaques usIng DarapladibThrombolysis in Myocardial Infarction (SOLID-TIMI 52) trial in patients after an acute coronary syndrome. Am Heart J. 2011;162:613-9. epub Sep 15.

41. Scirica BM, Bhatt DL, Braunwald E, Steg PG, Davidson J, Hirshberg B, et al. The design and rationale of the Saxagliptin Assessment of Vascular Outcomes Recorded in patients with diabetes mellitus-Thrombolysis in Myocardial Infarction (SAVOR-TIMI) 53 study. Am Heart J. 2011;162:818-25.

42. Kohli P, Desai N, Giugliano RP, Kim JB, Somaratne R, Huang F, et al. Design and rationale of the LAPLACE-TIMI 57 trial: a phase II, double-blind, placebo-controlled study of the efficacy and tolerability of a monoclonal antibody inhibitor of PCSK9 in subjects with hypercholesterolemia on background statin therapy. Clin Cardiol. 2012;35:385-91. 